\title{
A REPRESENTAÇÃO SOCIAL DA RESPONSABILIDADE SOCIAL CORPORATIVA
}

\author{
The social representation of the corporate social responsibility
}

\author{
Antonio Carlos de Almeida Guedes ${ }^{[a]}$, Roberto Luís da Silva Carvalho ${ }^{[b]}$, \\ Marcos Aguiar de Souza ${ }^{[c]}$, Edson Alves Souza Filho ${ }^{[\mathrm{d}]}$
}

\footnotetext{
[a] Mestre em Gestão e Estratégia em Negócios e professor do curso de Administração e Ciências Contábeis do Centro Universitário de Barra Mansa (UBM), Barra Mansa, RJ - Brasil.

${ }^{[b]}$ Licenciado em Matemática e professor substituto do Departamento de Matemática (ICE, UFRRJ), Seropédica, RJ -Brasil, email: robertoluis.carvalho@bol.com.br

${ }^{[c]}$ Doutor em Psicologia e professor adjunto do Departamento de Psicologia (IE, UFRRJ), Seropédica, RJ - Brasil.

[d]Pós - Doutor em Psicologia e professor associado do Departamento de Fundamentos da Educação e do curso de pós-graduação em Psicologia do Instituto de Psicologia (UFRJ), Seropédica, RJ - Brasil.
}

\begin{abstract}
Resumo
Atualmente tem sido defendida a importância de haver por parte das empresas uma atuação voltada para questões que contribuam direta ou indiretamente para a sociedade de uma maneira geral. Tais ações têm sido reunidas sob o rótulo de responsabilidade social corporativa (RSC). A lógica do discurso oficial e de alguns autores é que empresas socialmente responsáveis agregam valor a seus produtos, sendo privilegiadas pelos consumidores, o que tem sido questionado por diversos autores. É nesse sentido que no presente estudo o objetivo foi investigar a compreensão que os cidadãos têm a respeito das RSC, a partir da teoria das Representações Sociais. A utilização de tal teoria se justifica tendo em vista o objetivo de investigar a relação entre RSC e comportamento do consumidor. Participaram do estudo 168 indivíduos da cidade de Volta Redonda - RJ com média de idade de 27 anos, variando de 17 a 51 anos, de ambos os sexos. Para análise de dados foi realizada a Análise de Conteúdo das categorias obtidas a partir da pergunta "o que é Responsabilidade Social Corporativa?". A análise dos dados permitiu concluir que os participantes possuem representações sociais da RSC bastante próximas ao discurso dos órgãos oficiais, empresários e pesquisadores da área. Entretanto, também foi evidenciado que, apesar de haver esse entendimento, o consumo ético pretendido pelos defensores da RSC ainda não é uma realidade, já que 94\% informaram fazer uso de produtos "piratas".
\end{abstract}

Palavras-chave: Representações sociais. Responsabilidade social corporativa. Comportamento do consumidor. 


\begin{abstract}
Currently has been defended the importance to have participation on the part of the companies toward questions that contribute direct or indirectly for the society in a general way. Such actions have been congregated under the label of corporative social responsibility (RSC). The logic of the official discourse and of some authors is that socially responsible companies add value for its products, being privileged by consumers, what has been questioned for diverse authors. In this sense, the objective in the present study was to investigate the understanding that citizens have about RSC, using the Social Representations theory. The use of such theory is justified in view of the objective to investigate the relation between RSC and ethical behavior of the consumer. The participants were 168 individuals of the Volta Redonda city (Rio de Janeiro) with average of age of 27 years, varying from 17 to 51 years, of both sexes, that response the question "what is Corporative Social Responsibility?". The analysis of the data, with Content Analysis, allowed conclude that the participants possess social representations of the RSC similar to official agencies, entrepreneurs and researchers of the area discourse. However, also it was evidenced that, although to have this agreement, the ethical consumption intended by the defenders of the RSC not yet is a reality, since $94 \%$ had informed to make use of products "pirates".
\end{abstract}

Keywords: Social representations. Corporate social responsibility. Consumer's behavior.

\section{INTRODUÇÃO}

A responsabilidade social corporativa ou empresarial tem sido um dos temas mais explorados nos últimos anos. Sua lógica consiste na atribuição de responsabilidade às empresas por ações voltadas para o bem-estar social, de modo geral, podendo se referir a ações buscando beneficiar os próprios funcionários, os consumidores, o meio ambiente ou a sociedade de forma mais ampla.

A RSC compreende ações desenvolvidas para com a sociedade, tratamento adequado aos funcionários e bom relacionamento com os acionistas, clientes e fornecedores, com os stakeholders, enfim. Essas ações exigem periodicidade, método e sistematização e, principalmente, gerenciamento efetivo. $\mathrm{O}$ que se busca é a "autossustentabilidade de grandes e pequenas comunidades" (Melo Neto \& Froes, 2001).

A clara compreensão do que é a RSC e de que ações devem ser desenvolvidas para implementála parece ainda não ser consenso. Soares (2004), por exemplo, aponta no sentido que a leitura atenta dos discursos organizacionais revela palavras sequer pronunciadas e ainda, que existem contradições entre o que os membros das organizações assumem como sendo ética, moral e democracia e o que efetivamente é praticado no ambiente organizacional.
Carrol (1999) propõe um modelo conceitual onde inclui uma variedade de responsabilidades das empresas com a sociedade, esclarecendo que tais componentes de responsabilidade social empresarial estão além do objetivo de gerar lucros e obedecer à lei. O modelo engloba quatro tipos básicos de expectativas que refletem a visão de Responsabilidade Social Corporativa: econômica, legal, ética e discricionária.

As empresas têm uma responsabilidade de natureza econômica, considerando que produzem bens e serviços que a sociedade deseja e os vende para obter lucro, sendo isto a base do funcionamento do sistema capitalista.

Ao considerar a responsabilidade legal, a lógica é que a sociedade espera das empresas a realização da missão econômica que a elas cabe dentro dos requisitos estabelecidos pelo sistema legal. Obedecer à lei, assim, é uma das condições para a existência dos negócios.

A responsabilidade ética está relacionada ao fato de que a sociedade espera que as empresas tenham um comportamento ético em relação aos negócios, atuando dentro de uma concepção que, de forma positiva, ultrapassem os requerimentos legais.

Finalmente, a responsabilidade discricionária é entendida como o conjunto de ações tomadas pelas organizações e representam os papéis voluntários que 
as empresas assumem onde a sociedade não provê uma expectativa clara e precisa como nos outros componentes.

Diversas são as definições de RSC. A descrição exaustiva de tais definições seria pouco producente. Assim, foi adotada a definição proposta pelo Instituto Ethos de empresas e Responsabilidade Social Corporativa. Assim, a RSC pode ser definida como uma forma de conduzir os negócios que torna a empresa parceira e co-responsável pelo desenvolvimento social. Assim, uma empresa socialmente responsável é aquela que possui a capacidade de ouvir os interesses das diferentes partes (acionistas, funcionários, prestadores de serviço, fornecedores, consumidores, comunidade, governo e meio ambiente) e conseguir incorporálos ao planejamento e estratégia de suas atividades, buscando atender as demandas de todos, não apenas dos acionistas ou proprietários. Nesta abordagem, as empresas não deixariam de incluir o lucro como objetivo, porém, ao invés de priorizar a maximização de lucros de curto prazo as organizações deveriam buscar lucros a longo prazo, obedecer às leis e regulamentações, considerar o impacto nãomercadológico de suas decisões e procurar maneiras de melhorar a sociedade (Instituto Ethos, 2008).

A atuação de uma empresa socialmente responsável deve ultrapassar os domínios da empresa, não se restringindo ao cumprimento de obrigações legais, mas ampliando o seu envolvimento com comunidades locais e outras partes interessadas, entre elas: parceiros comerciais, fornecedores, clientes, autoridades públicas e ONGs, que atuam no entorno da empresa (Instituto Ethos, 2008; Comissão da Comunidade Europeia, 2001).

Ser socialmente responsávelé praticar ações com o intuito de complementar as ações insuficientes e precárias dos nossos governos, responsáveis pelo atual quadro de carências sociais presentes em nossa sociedade. Responsabilidade Social, portanto:

[...] é uma prática moral, orientada pela ética, que vai além das obrigações legais e econômicas, rumo às sociais, respeitando-se a cultura e as necessidades e desejos das pessoas. A responsabilidade social pressupõe consciência e compromisso das empresas com mudanças sociais. Impõe que elas reconheçam sua obrigação não só com os acionistas e clientes, mas também comos seres humanos, na busca de uma sociedade mais justa, honesta e solidária - uma sociedade melhor para todos (Passos, 2004, p. 166).
Apesar da existência de uma ampla gama de autores que defendem a RSC, existem sérias críticas à ideia de se atribuir às empresas algo que, para muitos, deveria ser responsabilidade do governo.

De acordo com Belizário (2006), o modelo neoliberal deu às empresas a tarefa de cuidar do sucesso financeiro das nações, cabendo ao Estado a promoção do bem-estar da sociedade e a regulação da atividade de mercados. É diante de uma clara falência do Estado, com notada incapacidade de lidar com aquilo que ele atribuiu a si mesmo, que começa a surgir a mudança nas regras do jogo. As empresas, com capital e agilidade para a resolução de problemas sociais complexos, poderiam ganhar espaço e poder superior ao governo. Assim, a oficialização desse papel pareceu ser uma boa saída.

Outro crítico da RSC é Guimarães (1984), o qual defende que a única função que pode ser cobrada de uma empresa é a geração de lucros e dividendos para os acionistas. Assim, a empresa que desenvolve ações voltadas para a sociedade, estaria ameaçando a própria existência num mercado cada vez mais competitivo.

Freitas (2002, p. 60) acrescenta que:

As empresas falam em seu nome e em nome de seus interesses, e o primeiro deles é não perder $[. .$.$] quando o econômico é critério$ decisivo, as empresas podem tomar decisões absurdas do ponto de vista do cidadão: queimar safras inteiras para elevar o preço do produto; aplicar no mercado financeiro e reduzir as atividades produtivas.

É importante considerar que tanto argumentos favoráveis como desfavoráveis à RSC são acessíveis ao cidadão comum. Assim, diferentes influências têm surgido a partir do discurso veiculado pelos órgãos oficiais, pelas empresas e pela mídia em geral, o que pode influenciar diferentes posicionamentos em relação ao tema e dar origem a comportamentos de consumo bastante diferenciados, possivelmente servindo de base para a explicação dos resultados obtidos em estudos que evidenciam uma postura não ética por parte dos consumidores, não privilegiando produtos de empresas socialmente responsáveis ou mesmo realizando compra de produtos falsificados.

Assim, diversos estudos buscam fazer uma análise crítica a respeito da RSC, dos interesses e das contradições entrelaçadas a este conceito. Tais estudos críticos em Administração podem, se 
não transformar a realidade organizacional e social, contribuir para o avanço de novas ideias, teorias e práticas. (2002, p.82),

Nos termos de Davel \& Alcadipani

Não há inovação organizacional sem o desenvolvimento de um espírito crítico apurado que ouse desvendar outras interpretações para a realidade social, instaurando novas possibilidades de ações que permitam às pessoas exercerem sua autonomia e sua consciência de interdependência social.

A questão da interdependência social acima destacada leva à consideração de que o interesse por ações de RSC deve reunir todos os lados da questão, englobando a sociedade como um todo. Uma vez que é de interesse para a sociedade que as empresas tenham a responsabilidade social como uma meta, também deve ser dada a devida ênfase ao comportamento dos cidadãos, principalmente na condição de consumidores, privilegiando produtos de empresas socialmente responsáveis.

Ao se referir à concepção que o cidadão tem da RSC, justifica-se a utilização da teoria das Representações Sociais (RS). A teoria das representações sociais oferece uma visão única da atividade cognitiva, uma vez que as pessoas não só têm convicções pessoais, mas também dão sentido aos eventos presentes no contexto social de que fazem parte. Elas não pensam simplesmente, mas buscam compartilhar seus pensamentos. Assim, na teoria das representações sociais a cognição é entendida como ação, mas uma ação na forma de representações externalizadas e comunicadas socialmente (Emler \& Ohana, 1993).

O estudo clássico em representações sociais, que apesar de não ser leitura definitiva é sem dúvida uma leitura obrigatória, foi realizado por Moscovici (1978), no qual se faz uma apresentação da teoria das representações sociais, utilizando-se como objeto a forma pela qual o público francês da década de 50 se apropria da psicanálise, transformando-a de saber científico em saber prático e do senso comum, socialmente compartilhado.

É o reconhecimento do caráter dinâmico das sociedades modernas que fez com que Moscovici, a partir do conceito de representações coletivas de Durkheim, desenvolvesse a teoria das representações sociais. Ao se referir ao conceito de representações coletivas originariamente desenvolvido em 1898, quando da publicação da obra "Da divisão social do trabalho," Durkheim fala de uma consciência coletiva que funde a sociedade e o indivíduo, funcionando como uma forma padronizada de perceber a realidade. Assim, seria através das representações coletivas que o indivíduo agiria e refletiria sobre sua ação.

Moscovici (1981) utiliza o termo representações sociais para referir-se ao conjunto de conceitos, proposições e explicações originados na vida cotidiana, no curso das comunicações interpessoais. Assim, elas equivalem aos mitos e sistemas de crenças das sociedades tradicionais, podendo também serem vistas como uma versão contemporânea do senso comum.

Ibañez (1988) considera que a dificuldade de definição da representação social já se faz presente no que se refere a sua formação, uma vez que esta integra um conjunto de conceitos distintos, tais como processos cognitivos, inserções sociais, fatores afetivos e sistemas de valores.

Por representação social, de acordo com Souza Filho (1988, p. 560),

[...] entendemos uma atividade de produção e comunicação de conhecimento, que é acionada quando um objeto ou evento, significativo e enigmático, aparece na vida social. Assim, o esforço de compreensão, de apropriação para tornar um objeto não-familiar em familiar, abstrato em concreto, ambíguo em definido, é um trabalho de representação social.

Para Jodelet (1984), a representação social refere-se a uma interpretação que permite pensar a nossa realidade cotidiana. É uma forma de conhecimento social, desenvolvido em conjunto por indivíduos e grupos, de modo a possibilitar um posicionamento diante de situações, eventos, objetos e comunicações a eles pertinentes.

Vala (1993) considera as representações sociais como um reflexo interno de uma realidade externa. Desse modo, elas se tornam reproduções mentais do mundo e dos outros. Existe, assim, uma gênese socialmente compartilhada, o que justifica o termo social quando se referindo a tais representações.

Em relação ao desenvolvimento das representações sociais, Moscovici (1981) destaca dois processos: a ancoragem e a objetificação. 
A ancoragem é definida como a inserção do objeto da representação em um marco de referência preexistente. De acordo com Billig (1993), a ancoragem reduz a ameaça do não familiar por meio de classificações enomes familiares. Issoé particularmente importante por que as coisas que não são classificadas ou que não têm nomes são estranhas, não existentes e ao mesmo tempo ameaçadoras. Assim, é possível incluir um conhecimento novo a um conjunto de conhecimentos já constituído.

Como salienta Joffe (2002), a ancoragem não deve ser considerada um processo individual de assimilação, uma vez que as ideias, imagens elinguagens compartilhadas por um grupo orientam a forma pela qual seus membros irão lidar com o não familiar.

O outro processo envolvido na formação das representações sociais, a objetificação, é definido como a concretização do abstrato. Termos como amor, tristeza, medo, são tratados pelo senso comum como coisas concretas, como se fossem de fato materializadas. Surge assim uma visão natural, socialmente aceita e constantemente reproduzida, visando delimitar aspectos que, na realidade são invisíveis. A objetificação tem, então, a função de permitir a um grupo melhor compartilhar a realidade em que vivem seus membros. É dessa forma que os conceitos científicos técnicos e abstratos são transformados em conceitos compreensíveis, familiares e seguros.

A objetificação é constituída pelos conteúdos dominantes ou centrais da representação. É isto que lhe confere seu caráter compartilhado. Entretanto, não se deve pressupor nesse compartilhar, a existência de pensamentos totalmente homogêneos. $\mathrm{Na}$ verdade, é diante do debate (e este ocorre a partir da existência de pontos de vista conflitantes), das conversas realizadas no dia-a-dia, que vão surgir as representações sociais (Billig, 1993).

Diante do contexto anteriormente exposto, considera-se que as RS servem de apoio à tarefa de entender como a RSC é percebida por indivíduos e grupos na sociedade. Ao mesmo tempo em que são identificados discursos que valorizam a RSC, existem na mídia discussões sobre aspectos como o imposto embutido na compra de qualquer produto industrializado e os recordes de arrecadação com impostos, entre outros, que favorece o desenvolvimento de representações que podem contribuirparaocomportamentonãoresponsável por parte do consumidor.

Das diversas definições existentes de Representações Sociais, no presente estudo será adotada a proposta por Morales (1994), ao considerar que as representações sociais têm algumas características específicas, como a) o caráter social de sua gênese; b) o fato de que são compartilhadas amplamente e distribuídas dentro de uma coletividade, caracterizando-se por uma forma específica de pensamento, sentimento e ações dos grupos sociais e c) uma estrutura interna dos processos implicados. A única ressalva a tal definição se refere ao aspecto compartilhado das representações sociais, o qual não acontece de forma tão uniforme como tem sido defendido por diversos autores.

A grande questão que se faz presente neste estudo é se o cidadão corresponde à lógica tão presente no discurso oficial ou mesmo de profissionais e teóricos interessados no tema: de que a responsabilidade social éantes de tudo um bom investimento para as empresas. Seguindo tal lógica, haveria socialmente uma maior valorização de produtos e serviços de empresas socialmente responsáveis.

É diante de tal quadro que no presente estudo, o objetivo principal é investigar a Representação Social da Responsabilidade Social Corporativa dos consumidores, especificamente no contexto da cidade de Volta Redonda - RJ.

\section{METODOLOGIA}

\section{Participantes}

Participaram do estudo 168 indivíduos da cidade de Volta Redonda - RJ, com média de idade de 27 anos, variando de 17 a 51 anos, diferenciados em relação ao sexo, sendo $72(42,9 \%)$ do sexo masculino e $96(57,1 \%)$ do sexo feminino, e segundo o grau de escolaridade (Tabela 1).

TABELA 1 - Distribuição de frequências do nível de escolaridade dos participantes

\begin{tabular}{lll}
\hline Escolaridade & Frequência & Porcentagem \\
\hline Fundamental & 20 & 11,9 \\
Médio incompleto & 22 & 13,1 \\
Médio completo & 49 & 29,2 \\
Superior incompleto & 40 & 23,8 \\
Superior completo & 24 & 14,3 \\
Pós-graduação & 13 & 7,7 \\
\hline Total & 168 & 100 \\
\hline
\end{tabular}




\section{Instrumentos}

Para a coleta dos dados referentes à Representação Social da Responsabilidade Social Corporativa e ao comportamento dos consumidores, foiutilizado um questionário (ANEXO1) cujo objetivo era (1) caracterizar a amostra em temos de sexo, idade, escolaridade, (2) identificar a Representação Social da Responsabilidade Social Corporativa.

\section{Procedimentos}

O instrumento para coleta dos dados relativos à Representação Social da RSC foi aplicado nos locais previamente escolhidos: o "SiderShopping" e o "Mercado Popular", ambos na cidade de Volta Redonda - RJ. O Sider Shopping é o maior Shopping da Cidade, e mesmo da região, sendo identificado como o principal local de compra de pessoas com poder aquisitivo mais elevado. O mercado popular é também conhecido como "Camelódromo" sendo local onde são comercializados produtos que mais diretamente atendem às classes mais populares, envolvendo, inclusive, produtos falsificados.

\section{Resultados e discussão}

Visando atingir o objetivo do presente estudo, foi realizada a análise de conteúdo das categorias obtidas a partir da pergunta "o que é Responsabilidade Social Corporativa?”. É interessante observar que foi considerado o número total de respostas dadas pelos participantes, havendo portanto, casos em que foi apresentada uma única resposta e casos em que estas chegaram ao número de cinco.

As categorias foram consideradas a partir do discurso dos participantes, não havendo a intenção de uma categorização prévia, com base na literatura. Entretanto, merece destaque que as categorias surgidas são referendadas na literatura disponível sobre o tema.

Inicialmente foram obtidas 109 categorias a partir das respostas dos 168 participantes do estudo. Num segundo momento, tais categorias de respostas foram reduzidas ao número de 13, considerando-se o conteúdo das mesmas. Assim, na Tabela 2 são apresentadas a frequência e a porcentagem de ocorrência das categorias relativas à $\mathrm{RS}$ da RSC.

TABELA 2 - Frequência e porcentagem sobre o que é responsabilidade social corporativa (RSC)

\begin{tabular}{lccc}
\hline Categorias & Frequência & Porcentagem & $\mathbf{X}^{2}$ \\
\hline Ações sociais & 78 & 30.71 & $149,868^{* *}$ \\
Ações meio ambiente & 51 & 20.08 & \\
Ações para funcionários & 17 & 6.69 & \\
Ações para qualidade de vida e saúde & 15 & 5.92 \\
Outras & 14 & 5.51 \\
Ética organizacional & 13 & 5.12 \\
Responsabilidade pelo entorno & 11 & 4.33 \\
Ações buscando retorno comercial & 11 & 4.33 \\
Aspectos legais impostos & 9 & 3.54 \\
Ações cotidianas do cidadão & 7 & 2.76 \\
Ações para clientes & 6 & 2.36 \\
Responsabilidade na produção & 6 & 2.36 \\
Ações assistencialistas & 5 & 1.97 \\
Ações culturais & 4 & 1.57 \\
Substituição ao Estado & 4 & 1.57 \\
Desenvolvimento sustentável & 3 & 1.18 \\
\hline
\end{tabular}

** Significativo ao nível 0,01 . 
A categoria “Ações Sociais” foi composta por respostas (Tabela 2) que identificaram a RSC como uma ação desenvolvida pela empresa para beneficiar de uma forma direta a sociedade em geral. Assim, são identificadas respostas como "Agir corretamente em relação à sociedade" e "Busca constante do bem-estar social".

A ocorrência de RS da RSC mais diretamente voltadas para a sociedade parece ser justificada diante dos argumentos de que é importante um reconhecimento por parte da sociedade de que determinada empresa desenvolve ações sociais. Assim, mesmo ações isoladas podem ganhar maior evidência num curto prazo de tempo, influenciando o comportamento dos consumidores diante do desempenho social que apresentam (Dacin \& Brown, 1997; Melo Neto \& Froes, 2001).

Na categoria "ações para o meio ambiente" (Tabela 2) foram incluídas respostas como "É a proteção que empresa dá ao meio ambiente" e "amenizar ou diminuir a poluição da natureza". Assim, tal categoria parece refletir o que vem sendo colocado como uma preocupação mundial, por organizações como o Green Peace, que desenvolvem boicotes diretos à ações de empresas que são prejudiciais ao ambiente. Temas como aquecimento global e escassez de água potável têm sido recorrentes numa discussão que atinge âmbito mundial. Recente tentativas de um pacto que reúnam ações ambientalmente responsáveis por parte de todos os países, amplamente divulgadas na mídia, podem ter contribuído para a ocorrência bastante acentuada desta categoria, associando a RSC ao cuidado e preservação do meio ambiente.

Tal contexto tem favorecido para uma maior visibilidade social das empresas que têm desenvolvido ações de responsabilidade social caracterizadas pelo cuidado com o ambiente (Volpon \& Macedo-Soares, 2007).

A categoria "ações para os funcionários" foi composta por manifestações do tipo "É pensar nos funcionários" e "Boas condições de vida aos familiares do empregados". Tal procedimento por parte das empresas justifica-se diante da teoria dos stakebolders, a qual considera o empregado como um elemento importante para o reconhecimento social da empresa.

A importância dada aos funcionários, de fato, vem sendo mais evidenciada nas organizações, sendo recente a utilização da expressão "colaboradores" na referência aos trabalhadores da empresa.
$\mathrm{Na}$ categoria "ações para a qualidade de vida e saúde" são encontradas respostas (Tabela 2) como "Melhorar a qualidade de vida" e "Preservar a qualidade de vida das comunidades". Tal categoria foi a de quarta maior incidência.

A categoria "Etica organizacional" foi composta por respostas como "Ética para conduzir os negócios" e "Políticas organizacionais morais e éticas" (Tabela 2). Tal categoria está de acordo com o discurso da RSC como uma postura ética que as empresas devem assumir para com a sociedade. Nessa categoria está incluída a noção da RSC como algo relacionado a um valor mais amplo, mais do que um simples investimento por parte da empresa, tal como tem sido evidenciado na literatura (Melo Neto \& Froes, 2001).

$\mathrm{Na}$ categoria "Responsabilidade pelo entorno" estão presentes representações sociais da RSC que se referem a "Responsabilidade com a comunidade" e Responsabilidade com o local onde estão instaladas". A ideia básica contida nesta categoria faz menção à importância da localização da empresa para o benefício a ser por ela proporcionado, indicando que as pessoas mais próximas devem ser seus maiores beneficiados.

A categoria "Retorno comercial" foi composta por representações sociais da RSC como "Método para obter confiabilidade dos clientes e dos empregados" e "Entrosamento para as empresas venderem mais produtos". Assim, tal categoria reúne representações que consideram a RSC como uma ferramenta estratégica: um investimento e não um gasto da empresa, corroborando a visão que tem sido apontada na literatura por muitos autores.

A categoria "Ações legais" foi composta por respostas como "Performance social imposta às empresas" e "Regularidade fiscal". Nessa categoria são englobados dois aspectos. O primeiro se refere à obrigação da empresa de cumprir com o que legalmente lhe é devido. O outro se refere a ações voltadas para a sociedade de maneira geral, que são desenvolvidas por força de lei. Apesar de não haver leis diretas obrigando as empresas a desenvolverem um ou outro tipo de ação de responsabilidade social, diversos benefícios são esperados pelo desenvolvimento de tais ações.

A categoria "Ações cotidianas do cidadão" (Tabela 2) é composta por representações como "guardar pilhas velhas em locais apropriados" e "saber separar o lixo". Assim, é evidenciada a presença de representações que se referem ao 
cidadão e não às empresas. É possível que a ocorrência desta categoria se deva ao fato de haver campanhas desenvolvidas pelas empresas que buscam uma conscientização do cidadão.

Cartilhas, treinamentos, oficinas, disponibilização de locais para coleta seletiva de lixo, desenvolvimento de programas para lidar com resíduos como óleo de cozinha usado, são exemplos de ações de responsabilidade social praticadas pelas empresas que têm como alvo principal a participação efetiva dos cidadãos.

$\mathrm{Na}$ categoria "Ações para clientes" são encontradas representações como "Respeito com os consumidores" e "atender bem os clientes". Assim, evidencia-se nesta categoria uma preocupação direta com os consumidores que pode estar baseada em dois principais aspectos. O primeiro é a fidelização do cliente, que vem se tornando cada vez mais exigente (Belizário, 2006) e uma postura socialmente responsável que vai além da simples venda de um produto. Assim, o benefício maior ao cliente é enfatizado nesta categoria.

$\mathrm{Na}$ categoria "Responsabilidade na produção" são encontradas representações como "Produtos produzidos com responsabilidade" e "Produtos que atendam ou superam as necessidades dos clientes". Evidencia-se nesta categoria a necessidade das empresas oferecerem produtos que satisfaçam seus clientes de maneira geral.

A responsabilidade na produção seria então caracterizada pelo oferecimento de produtos alta qualidade, alta durabilidade e sem riscos de danos à segurança e à saúde.

A categoria nomeada "Ações assistencialistas" (Tabela 2) é categorizada por representações como "dar trabalho para as pessoas carentes" e "Respeito com a desigualdade". Assim, é evidenciada a necessidade da empresa dar algo em troca ao lucro que obtém. A concepção assistencialista aparece na literatura sendo considerada como uma das visões iniciais da RSC (Barich \& Kotler, 1991).

$\mathrm{Na}$ categoria "Ações culturais" estão representações como "Responsabilidade cultural" e "Desenvolvimento cultural". Assim, a RSC é entendida como uma ação que visa direta ou indiretamente valorizar a cultura. Patrocínio de peças teatrais e outras ações valorizando e incentivando a cultura podem ser consideradas nesta categoria.

A categoria "Substituição ao Estado" é composta de representações como "Ser responsável pelos problemas sociais" e "lutar contra a mão-deobra infantil". Assim, às empresas, conforme as representações observadas nesta categoria, devem ser atribuídas responsabilidades que anteriormente eram do Estado. Nesta categoria observam-se alguns aspectos relativos às críticas que a RSC tem recebido por parte de diversos autores que consideram ser responsabilidade do Estado lidar com diversas das questões que, de uma maneira ou de outra vêm sendo exigidas das empresas.

Finalmente, na categoria "Desenvolvimento sustentável" são encontradas representações como "diretrizes para o desenvolvimento sustentável" e "Adoção de práticas sustentáveis". A preocupação com o ambiente e com a sociedade de maneira geral aparecem nesta categoria, buscando uma conciliação entre objetivos econômicos e ambientais.

A categoria "outras" é composta por respostas que não puderam ser enquadradas nas categorias anteriores e que eram ou pouco informativa (como "coisa legal") ou de pouca frequência (como "Condições e vontade de ação").

A análise das respostas dos participantes do estudo permitiram, então, o entendimento de que as RS da RSC refletem aquilo que vem sendo discutido tanto por parte dos autores como pela mídia em geral. Assim, é possível dizer que os participantes possuem representações sociais bastante próximas à forma pela qual a RSC é compreendida, indicando uma relação direta entre o universo reificado e o universo consensual.

Neste estudo, também foi fonte de interesse, analisar as respostas da RSC por grupos de escolaridade, sendo considerado inicialmente que os indivíduos com maior grau de escolaridade possuiriam maior nível de informação em relação a RSC. Entretanto, como pode ser observado na Tabela 3, as representações dos grupos diferenciados pela escolaridade se aproximaram bastante, sendo significativamente diferenciadas apenas no que diz respeito à frequência em que surgiram. 
TABELA 3 - Frequência e porcentagem das RS da RSC por nível de escolaridade

\begin{tabular}{|c|c|c|c|c|c|c|c|c|}
\hline \multirow[t]{2}{*}{ Categorias } & \multicolumn{2}{|c|}{ Fundamental } & \multicolumn{2}{|c|}{ Médio } & \multicolumn{2}{|c|}{ Superior } & \multicolumn{2}{|c|}{ Pós-Graduação } \\
\hline & f & $\%$ & f & $\%$ & f & $\%$ & f & $\%$ \\
\hline Ações sociais & 8 & 38,10 & 26 & 36,62 & 36 & 29,51 & 8 & 25 \\
\hline Ações meio ambiente & 6 & 28,57 & 17 & 23,94 & 24 & 19,67 & 4 & 12,5 \\
\hline Ações para funcionários & 0 & 0 & 1 & 1,42 & 14 & 11,47 & 2 & 6,25 \\
\hline Ações para qualidade de vida e saúde & 3 & 14,29 & 5 & 7,04 & 5 & 4,10 & 1 & 3,12 \\
\hline Outras & 2 & 9,52 & 4 & 5,63 & 5 & 4,10 & 0 & 0 \\
\hline Ética organizacional & 0 & 0 & 2 & 2,82 & 7 & 5,74 & 4 & 12,5 \\
\hline Responsabilidade pelo entorno & 0 & 0 & 0 & 0 & 8 & 6,56 & 3 & 9,39 \\
\hline Ações buscando retorno comercial & 0 & 0 & 2 & 2,82 & 4 & 3,28 & 5 & 15,63 \\
\hline Aspectos legais impostos & 0 & 0 & 4 & 5,63 & 5 & 4,10 & 0 & 0 \\
\hline Ações cotidianas do cidadão & 1 & 4,76 & 3 & 4,22 & 3 & 2,46 & 0 & 0 \\
\hline Ações para clientes & 0 & 0 & 3 & 4,22 & 2 & 1,64 & 1 & 3,12 \\
\hline Responsabilidade na produção & 0 & 0 & 3 & 4,22 & 1 & 0,81 & 2 & 6,25 \\
\hline Ações assistencialistas & 1 & 4,76 & 0 & 0 & 0 & 0 & 0 & 0 \\
\hline Ações culturais & 0 & 0 & 0 & 0 & 3 & 2,46 & 1 & 3,12 \\
\hline Substituição ao Estado & 0 & 0 & 1 & 1,42 & 2 & 1,64 & 1 & 3,12 \\
\hline Desenvolvimento sustentável & 0 & 0 & 0 & 0 & 3 & 2,46 & 0 & 0 \\
\hline \multirow[t]{2}{*}{ Total } & 21 & 100 & 71 & 100 & 122 & 100 & 32 & 100 \\
\hline & \multicolumn{8}{|c|}{$X^{2}=69,532 *$} \\
\hline
\end{tabular}

* Significativo ao nível de 0,05 .

Entre os participantes da pesquisa com ensino fundamental, predominaram RS da RSC relativas a ações sociais $(38,10 \%)$ seguidas de representações sociais relativas ao meio ambiente $(28,57 \%)$ e ações voltadas para qualidade de vida e saúde $(14,29 \%)$. Entre os indivíduos com ensino médio, predominaram representações associadas a ações sociais $(36,62 \%)$, seguidas de representações indicativas de ações para o meio ambiente $(23,94 \%)$ e qualidade de vida e saúde (7,04\%). Em relação aos indivíduos com nível superior predominaram representações voltadas para ações sociais $(29,51 \%)$, seguidas de ações voltadas para o meio ambiente $(19,67 \%)$ e ações para funcionários $(11,47 \%)$. Finalmente, nos participantes com escolaridade ao nível da pósgraduação predominaram representações relativas a ações sociais $(25 \%)$, seguidas de representações relacionadas à busca de retorno comercial $(15,63 \%)$ e de ações para o meio ambiente e ética organizacional, ambas com $12,5 \%$ das respostas.

Assim, apesar da diferença significativa encontrada, observa-se que nos quatro grupos predomina a RSC entendida como uma ação de cunho social desenvolvida pela empresa, categoria em geral referendada pela literatura como a mais abundante, a partir da própria expressão Responsabilidade Social Corporativa. As representações relacionadas a ações para o meio ambiente ocorreram em segundo lugar nos indivíduos com ensino fundamental, médio e superior. Tal ocorrência também parece justificada pela recorrência da associação de ações ambientais à principal preocupação nas sociedades atuais.

As diferenças entre os grupos, então, se referem à segunda categoria de maior frequência 
encontrada nos indivíduos com nível de pósgraduação e na terceira categoria de maior frequência entre os demais grupos.

No grupo com pós-graduação a segunda categoria de maior ocorrência foi "ações buscando retorno comercial". Esta categoria se refere a um dos pontos de discussão sobre a importância da RSC para a própria empresa, como defende Melo Neto \& Froes (2001). Entretanto, é uma categoria que reflete um tema menos debatido pela mídia e, provavelmente, menos acessível ao cidadão comum.

Em relação às categorias que aparecem em terceiro lugar nos grupos é que se explica a diferença significativa encontrada. Assim, entre os indivíduos com ensino fundamental entre os de ensino médio, predominaram ações para a qualidade de vida e saúde. É possível que tais categorias sejam mais evocadas tendo em vista o maior acesso dessas pessoas a ações desenvolvidas pelas empresas com tal interesse.

Em relação aos indivíduos com ensino superior a categoria que ocorre em terceiro lugar está relacionada com uma preocupação com os funcionários de uma maneira geral. De fato, como apontado por Belizário (2006), este tipo de ação, juntamente com aquelas voltadas para o meio ambiente, é a que tem melhor retorno para a empresa. É possível também que os maiores divulgadores das ações desenvolvidas pelas empresas sejam os próprios funcionários.

Finalmente, em relação aos participantes com pós-graduação o terceiro lugar foi ocupado em conjunto por representações associadas ao meio ambiente e à ética organizacional. Em relação ao meio ambiente, também é possível afirmar haver uma recorrência bastante relevante em relação ao tema pelos autores e pela mídia em geral. Entretanto, a ética organizacional se refere a um entendimento mais aprofundado da RSC, pouco discutida no contexto dos grupos de ensino fundamental, médio e superior.

Comparações adicionais das RS da RSC foram realizadas em função do sexo e do local de coleta dos dados. Em ambos os casos, não foram encontradas diferenças significativas. É interessante observar, então, que as RS da RSC são bastante similares entre homens e mulheres e entre os frequentadores tanto do mercado popular e do Sider Shopping, ambos na cidade de Volta Redonda.

Ainda visando atingir o objetivo do estudo, foi levantada a frequência e porcentagem de consumidores que já adquiriram produtos piratas. Assim, a maior parte dos consumidores 94 $\%$ realiza compra de produtos piratas (Tabela 4).

TABELA 4 - Já comprou produto pirata?

\begin{tabular}{cccc}
\hline Compra & Frequência & Porcentagem & $\mathbf{X}^{2}$ \\
\hline Sim & 158 & 94 & $130,38^{* *}$ \\
Não & 10 & 6 & \\
\hline Total & 168 & 100 & \\
\hline
\end{tabular}

** Significativo ao nível 0,01 .

De acordo com os dados da Tabela 4, verifica-se que a influência da RS da RSC não está intimamente ligada ao comportamento dos consumidores, assim é preciso que ações sejam desenvolvidas buscando fazer com que a RSC não seja um gasto, mas sim um investimento, como pretendido por diversos autores. Para tanto, é necessário que exista uma ampla discussão sobre o tema, que atualmente está atravessado por questões como os altosimpostos arrecadados pelogoverno, que aparecem de forma embutida no preço de diversos produtos.

\section{CONCLUSÕES}

Como discutido anteriormente, as Representações Sociais da Responsabilidade Social Corporativa encontradas no presente estudo são aquelas mais recorrentemente discutidas pelos autores da área e pela mídia de uma maneira geral. É assim que se pode explicar a maior ocorrência de representações associadas a ações sociais e ao meio ambiente. Observase, assim, como previsto pela teoria das Representações Sociais, uma forte relação na forma como o objeto social considerado no presente estudo é entendido pelo universo reificado e pelo universo consensual.

A Responsabilidade Social Corporativa, de fato, é algo que deve ser valorizado por todos na sociedade: governo, empresas e cidadãos. Assim, é preciso que caminhem juntos os temas que sejam identificados como relevantes para a compreensão da RSC da forma como pretendida na sociedade.

É necessário que estudos futuros sejam realizados com o intuito de investigar por que apesar de haver pleno entendimento do que é a Responsabilidade 
Social Corporativa, havendo, portanto, congruência comoqueédiscutido pelos órgãos oficiais, pelaacademia, pela mídia e pela população, de uma maneira geral, tais representações são insuficientes para guiarem o comportamento ético de consumo dos cidadãos. Em outras palavras, que outras representações poderiam estar presentes para a existência dessa barreira entre representações sociais e comportamento.

Finalizando, é possível que a concepção que os cidadãos têm sobre o imposto existente em cada produto comprado ou mesmo a concepção que têm sobre os reais interesses das empresas (lucro ou benefício dos consumidores) forneçam maiores informações sobre o comportamento não ético por parte dos consumidores.

\section{REFERÊNCIAS}

Barich, H., \& Kotler, P. S. (1991). A framework for marketing image. Sloan Management Review, 32(2), 94-104.

Belizário, F. B. (2006). O lugar da comunicação no discurso da responsabilidade social: Entre o cinismo e a alienação. UNIrevista, 1(3), 1-12.

Billig, M. (1993). Studying the thinking society: social representations, retoric and attitudes. In G. M. Breakwell \& D. V. Canter. Empirical approaches to social representations. Oxford: Claredon Press.

Carrol, A. B. (1979). A three dimensional conceptual model of corporate performance. Academy of Managemet Review, 4(4), 497-505.

Comissão das Comunidades Europeias. (2001). Livro verde: Promover um quadro europeu para a responsabilidade social das empresas. Bruxelas. Recuperado 11 nov. 2008, disponível http://eurl e x . e u r o p a . e u / L e x U r i S e r v / LexUriServ.do?uri=COM: 2001:0366:FIN:PT:PDF

Dacin, P. A., \& Brown, T. J. (1997). The company and the product: Corporate association and consumer product response. Journal of Marketing, 61(1), 68-84.

Davel, E., \& Alcadipani, R. (2003). Estudos críticos em administração: A produção cientifica brasileira nos anos 1990. RAE - Revista de Administração de Empresas, 43(4), 72-85.

Emler, N., \& Ohama, J. (1993). Studying social representations in children: Just on wine in new botlles? In G. M. Breakwell, \& D. V. Canter. Empirical Approaches to Social Representations (pp. 6389). Oxford: Clarendon Press.
Guimarães, H. W. M. (1984). Responsabilidade social da empresa: Uma visão histórica de sua problemática. Revista de Administração de Empresas, 24(4), 211-219.

Ibañez, T. G. (1988). Representaciones sociales, teoria y método. Ideologias de la vida cindidiana. Barcelona: Sendai.

Instituto Ethos de Empresa Responsabilidade Social. Recuperado 14 mar. 2008, disponível http://www.ethos.org.br/ DesktopDefault.aspx?Alias =Ethos\&Lang=pt$\mathrm{BR} \& \mathrm{TabID}=3334$

Jodelet, D. (1984). Représentation sociale: phénomènes, concept et théorie. In S. Moscovici (Ed.). Psychologie sociale. Paris: Presses Universitaires de France.

Joffe, H. (2002). Social representations and health psychology. Social Science Information, 41(4), 559-580.

Melo Neto, F. P., \& Froes, C. Q. (2001). Gestão da responsabilidade social corporativa: $O$ caso brasileiro. Rio de Janeiro: Qualitymark.

Morales, J. F. (1994). Psicologia Social. Madrid: McGraw-Hill.

Moscovici, S. (1978). A representação social da psicanálise. Rio de Janeiro: Zahar.

Moscovici, S. (1981). On social representation. In J. P. Forgas (Ed.). Social cognition: Perspectives in everyday life (pp. 181-209). London: Academic Press.

Passos, E. (2004). Ética nas organizações. São Paulo: Atlas.

Souza Filho, E. A. (1988). Universitários brasileiros no exterior: Uma análise psicossocial. Ciência e Cultura, 40(6), 559-565.

Vala, J. (1993). Representações sociais: Uma psicologia social do pensamento social. In J. Vala \& M. B. Monteiro (Ed.). Psicologia social (pp. 351-384). Rio de Janeiro: Fundação Calouste Gulbenkian.

Volpon, C. T., \& Macedo-Soares, T. D. L. V. A. (2007). Alinhamento estratégico da responsabilidade socioambiental corporativa em empresas que atuam em redes de relacionamento: resultados de pesquisa na Petrobras. Revista de Administração Pública, 41(3), 391-418.

Recebido: 05/12/2008 Received: 12/05/2008

Aprovado: 10/01/2009 Approved: 01/10/2009

Revisado: 18/09/2009 Reviewed: 09/18/2009 


\section{ANEXO 1}

Este questionário faz parte de uma pesquisa que tem como objetivo investigar como as pessoas compreendem determinados aspectos relacionados às organizações.

Você não é obrigado a respondê-lo, mas sua participação é essencial para que consigamos alcançar nossos objetivos, proporcionando um atendimento cada vez mais voltado para as necessidades do consumidor por parte da empresas.

Sexo: ( ) Masculino ( ) Feminino

Idade: anos

Cidade em que reside:

Grau de escolaridade:

( ) Ensino fundamental

( ) Ensino médio incompleto

( ) Ensino superior incompleto

( ) Ensino médio completo

( ) Ensino superior completo

( ) Pós-graduação

1. O que é responsabilidade social corporativa (RSC) em sua opinião?

2. Você compraria produtos de alguma empresa que não seja responsável socialmente?

( ) Sim

( ) Não

3. Você já comprou algum produto pirata?

( ) Sim ( ) Não 